\title{
INTERAÇÕES DISCURSIVAS EM PEQUENO GRUPO DURANTE UMA ATIVIDADE INVESTIGATIVA SOBRE DETERMINAC̣ÃO DA ACELERAÇÃO DA GRAVIDADE
}

\begin{abstract}
RESUMO: A pesquisa em ensino de ciências tem mostrado a importância de estudos sobre os discursos presentes na sala de aula para a compreensão dos processos de ensino-aprendizagem. O propósito deste trabalho é analisar as interações discursivas que surgiram em um pequeno grupo de alunos de Ensino Médio durante a realização de uma atividade investigativa sobre determinação da aceleração da gravidade. Apresentamos os aportes teóricos em que nos baseamos e a técnica experimental utilizada pelos alunos para realizar a experiência e descrevemos a atividade investigativa aplicada em sala de aula. A análise das falas de um dos grupos de alunos evidenciou a presença tanto de conversação acumulativa como de conversação exploratória entre eles. Além disso, identificamos, no discurso dos estudantes, questões de informação básica e também de alto nível cognitivo. Essas últimas contribuíram fortemente para a solução ao problema e foram formuladas por alunos que participaram pouco da discussão, o que nos levou a chamar a atenção para o papel que os estudantes que menos falam na interação em pequeno grupo podem ter para a resolução de problemas de caráter investigativo.
\end{abstract}

Palavras-chave: Interação discursiva. Pequeno grupo. Atividade investigativa.

\section{DISCURSIVE INTERACTIONS IN A SMALL GROUP DURING AN INQUIRY-BASED ACTIVITY ON DETERMINING THE ACCELERATION OF GRAVITY}

ABSTRACT: Research in science education showed the importance of studies about discourse in the classroom to understand the processes of teaching and learning. The aim of this study is to analyze the discursive interactions that have arisen in a small group of high school students during an inquiry-based activity on determining the acceleration of gravity. We present the theoretical framework used in the research, the inquirybased activity proposed to the class and the experimental technique used by students to carry out the experiment. The analysis of the speeches of one students' group revealed the presence of both cumulative and exploratory conversation among them. Besides, basic information questions and wonderment questions were identified in the students' discourse. These wonderment questions had an important contribution to the solution of the problem and they were made by the students who had little participation in the discussion, which indicates the role these students may have to solve inquiry-based problems with their peers.

Keywords: Discursive interaction. Small group. Inquiry-based activity.

\section{Marta Maximo Pereira*}

${ }^{*}$ Doutoranda em Ensino de Ciências (Física) pelo Programa de Pós-Graduação Interunidades em Ensino de Ciências da Universidade de São Paulo (USP). Professora do Ensino Básico, Técnico e Tecnológico do Centro Federal de Educação Tecnológica Celso Suckow da Fonseca (CEFET/RJ).

E-mail: martamaximo@yahoo.com 


\section{INTRODUÇÃO E OBJETIVOS}

Nos últimos anos, a pesquisa em ensino de ciências tem obtido resultados que evidenciam a importância das atividades em grupo e da interação entre os alunos, e deles com o professor, para a aprendizagem escolar (MERCER, 1997; CAZEN, 2001; MORTIMER e SCOTT, 2003). Como as pessoas estabelecem relações umas com as outras de modo inevitavelmente discursivo, estudos sobre os discursos presentes na sala de aula (MEHAN, 1979; MORTIMER e SCOTT, 2002) e sobre linguagem (LEMKE, 1990; ROTH, 2005) são também muito atuais e representam um campo bastante frutífero de investigações.

Tais trabalhos indicam que conhecer o quê, como, por quê e para quê se fala na sala de aula pode auxiliar na compreensão sobre os processos de ensino-aprendizagem e sobre as interações sociais que nela ocorrem. Em especial, estudar as interações discursivas entre pares permite evidenciar o grau de envolvimento dos alunos na atividade proposta, os processos de construção mediada de significados e como tais interações favorecem a aprendizagem conceitual e o desenvolvimento de habilidades relativas à solução de problemas.

Tendo em vista essa perspectiva e considerando as contribuições da pesquisa em ensino de ciências, este trabalho tem por objetivo responder às seguintes questões: como um pequeno grupo de alunos se vale das interações discursivas com os pares para atribuir sentido a uma experiência e para encontrar uma solução satisfatória a um problema experimental aberto, de caráter investigativo? É possível identificar, nessas interações em pequeno grupo, elementos e características mapeados pela pesquisa em ensino de ciências em outros contextos?

Não se pretende com este trabalho buscar generalizações por intermédio da aplicação, a esses problemas de pesquisa em especial, de alguns conceitos e formulações já estabelecidos. Foi realizado um estudo do ponto de vista discursivo, com a descrição e a problematização de como os estudantes interagem discursivamente em pequeno grupo. Tal investigação parece ser relevante para o entendimento do papel da interação entre pares para a resolução de problemas de caráter investigativo e para a compreensão dos limites e possibilidades de uma atividade investigativa no contexto de aulas de Física inseridas na realidade educacional aqui descrita e analisada.

\section{2- REFERENCIAL TEÓRICO}

Este trabalho se insere na perspectiva de pesquisa sócio-histórico-cultural, ancorada, sobretudo, nos trabalhos de Vigostki (2007, 2009), e nos estudos dos processos de construção mediada de conhecimentos por meio do discurso em salas de aula (MERCER, 1997; CAZDEN, 2001; CHIN e BROWN, 2002). São explicados, a seguir, quais elementos apresentados por esses autores foram utilizados neste texto e de que modo tais elementos foram articulados para dar conta das questões de pesquisa. 
De acordo com Vigotski (2007), os processos mentais superiores do indivíduo têm sua origem em processos sociais e o desenvolvimento cognitivo é a transformação dessas relações sociais em funções mentais. Em sua "lei genética geral do desenvolvimento cultural", Vigotski afirma que

toda função no desenvolvimento cultural da criança aparece duas vezes: primeiro no nível social e, mais tarde, no nível individual; primeiro entre pessoas (interpsicológica), então dentro da criança (intrapsicológica). (VIGOTSKI, 2007, p. 57-58)

Para encontrar relações entre o processo de desenvolvimento e a capacidade de aprendizado, deve-se definir, de acordo com Vigotski (2007), pelo menos dois níveis de desenvolvimento. O primeiro, denominado nivel de desenvolvimento real (NDR), diz respeito às funções mentais que já se estabeleceram de forma completa na estrutura cognitiva do sujeito, ou seja, o NDR é caracterizado por aquilo que o indivíduo consegue fazer de maneira autônoma, sem o auxílio de outras pessoas. O segundo nível, chamado nível de desenvolvimento potencial (NDP), diz respeito àquilo que o sujeito é capaz de realizar apenas sob a orientação de outra pessoa ou em colaboração com parceiros mais capazes.

Para estabelecer uma dinâmica entre esses dois níveis e entender como se dá o curso interno do desenvolvimento, Vigotski (2007) elabora o conceito de zona de desenvolvimento proximal (ZDP), que é justamente a região entre o NDR e o NDP do indivíduo. Para Vigotski (2007, p. 103),

[...] um aspecto essencial do aprendizado é o fato de ele criar a zona de desenvolvimento proximal; ou seja, o aprendizado desperta vários processos internos de desenvolvimento, que são capazes de operar somente quando a criança interage com pessoas em seu ambiente e quando em cooperação com seus companheiros.

É por intermédio de uma aprendizagem que se adianta ao desenvolvimento, no sentido de promovê-lo, que se forma a ZDP. Mas, como ela é criada? De acordo com Moll (1990, p.11) apud Daniels (2003, p. 81),

Vygotsky nunca especificou as formas de assistência social aos alunos que constituem uma ZDP. [...] Ele escreveu sobre colaboração e direção, e sobre auxiliar crianças "pela demonstração, conduzindo questões, e pela introdução de elementos iniciais da resolução da tarefa" [...] mas não apresentou especificações além dessas prescrições gerais.

Considerou-se, neste estudo, assim como em Newman, Griffin e Cole (1989), que a ZDP é criada pela negociação entre o aluno e o parceiro mais capaz, em situações de aprendizagem.

Como as pessoas interagem entre si de modo eminentemente discursivo, as interações sociais são sempre mediadas pela linguagem. Sendo assim, a indissociabilidade defendida por Vigotski (2009) entre pensamento e linguagem indica que investigar o discurso dos estudantes pode nos auxiliar na compreensão de seus processos de aprendizagem, já que é por meio da interação social que ocorrem o 
intercâmbio de significados entre os sujeitos e a apreensão dos significados compartilhados socialmente. De acordo com Mortimer e Scott (2003, p. 10):

\begin{abstract}
segundo a perspectiva sociocultural, se queremos investigar os modos pelos quais as pessoas tipicamente pensam sobre o mundo a seu redor, devemos começar investigando os modos pelos quais elas falam e se comunicam sobre o mundo. Se estamos interessados, por exemplo, em como ocorre a aprendizagem nas aulas de ciências, então devemos começar analisando a conversação e outros meios de comunicação nas aulas de ciências.
\end{abstract}

Assim, é interessante estudar as interações de tipo discursivo porque elas permitem que sejam praticadas e desenvolvidas formas de raciocinar com a linguagem e por intermédio dela. Considera-se, em especial, que a conversação em contextos de atividades compartilhadas socialmente permite ao sujeito aprender muitas coisas com pessoas que não são necessariamente seus professores. Além disso, a discussão e o debate com outras pessoas, em pé de igualdade, pode ampliar a compreensão do indivíduo sobre determinado tema, pois o leva a pensar junto a outros, reavaliando suas ideias e as de seus parceiros.

Uma discussão em pé de igualdade ocorre frequentemente entre pares e pode ser profícua, entre outras razões, porque proporciona uma atenuação das relações de poder entre os interlocutores. Na medida em que, em geral, aqueles que dialogam possuem uma base bastante semelhante de conhecimentos e experiências anteriores, isso os ajuda a estar mais confiantes e confortáveis em uma situação de embate de ideias. Entre pares, o sujeito se sente menos avaliado e menos pressionado a fornecer uma resposta "correta" ou "esperada".

Por tudo isso, defendemos que é importante levar em conta, na pesquisa em ensino de ciências, a interação discursiva que os estudantes estabelecem com seus pares, a qual pode facilitar a construção de conhecimentos e o desenvolvimento de habilidades. Além disso, temos que considerar a presença do parceiro mais capaz (VIGOTSKI, 2007) também na interação entre pares, já que alguns alunos podem auxiliar seus companheiros na resolução de uma tarefa que não seria concluída sem a sua contribuição. Analisar as atividades desenvolvidas em pequeno grupo permite evidenciar que não só o professor pode atuar como parceiro mais capaz, mas alguns alunos do próprio grupo também podem fazê-lo.

De acordo com Cazden (2001), saber comunicar-se de forma efetiva e trabalhar em grupo (com pessoas com diferentes perfis e estilos de trabalho) são habilidades necessárias tanto para conseguir um bom emprego como para participar de uma sociedade em transformação. Assim, essas capacidades deveriam ser desenvolvidas na escola, por intermédio de atividades destinadas a esses fins.

A perspectiva do ensino por investigação (AZEVEDO, 2004) pode possibilitar o desenvolvimento de tais habilidades pelos estudantes, na medida em que ela pressupõe o trabalho coletivo, a discussão e a negociação de significados para a resolução do problema proposto.

Para Mercer (1997), algumas condições favoráveis para uma atividade discursiva frutífera em sala de aula seriam: os pares precisam falar para realizar a tarefa; 
a atividade deve ser planejada com o objetivo de promover a cooperação entre os participantes; todos os alunos envolvidos devem compreender a atividade e seu propósito; as regras da atividade devem possibilitar a troca de ideias e a participação de todos; os alunos devem compartilhar as mesmas ideias sobre o que é relevante na discussão. Por suas características, uma atividade investigativa pode ser realizada em um ambiente propício às interações discursivas, tal com descrito por Mercer (1997).

Mas por que o interesse, neste trabalho, em analisar as interações discursivas que ocorrem em um pequeno grupo de alunos durante uma atividade investigativa? De acordo com Barnes e Todd (1978, p. 127) apud Mercer (1997, p. 105),

consideramos que colocar a responsabilidade nas mãos dos alunos muda a natureza da aprendizagem ao obrigá-los a negociar seus próprios critérios de importância e veracidade. Se a educação é preparar as pessoas para uma vida de adulto responsável, este tipo de aprendizagem tem um lugar importante no repertório das relações sociais que os professores têm a sua disposição.

Entretanto, o trabalho em grupo, por si só, não garante a aprendizagem; ela depende do propósito da atividade proposta, de como o professor a planeja e a desenvolve por meio de interações com os estudantes. Depende, ainda, do engajamento dos alunos e das ações desencadeadas pela atividade.

Tendo clara a importância das atividades discursivas em sala de aula, como analisar o discurso dos alunos? Reconhecendo que nem todos os tipos de interação discursiva e de colaboração têm a mesma importância para a aprendizagem dos estudantes ou a influenciam do mesmo modo, foram utilizados alguns aportes disponíveis na literatura para investigar o discurso dos estudantes.

O primeiro deles diz respeito ao tipo conversação que pode aparecer quando os alunos interagem discursivamente em grupo. Segundo Mercer (1997), existem três tipos de conversação entre os alunos: acumulativa, disputativa e exploratória. São apresentadas, a seguir, as características de cada uma delas.

$\mathrm{Na}$ conversação acumulativa, o discurso do grupo se caracteriza por afirmações, repetições e confirmações das ideias e opiniões dos colegas; é estabelecida uma relação de solidariedade no grupo, pois os alunos constroem positivamente, mas não criticamente, sobre aquilo que os outros estudantes dizem.

Já na conversação disputativa, o discurso do grupo é dominado por afirmações e refutações, com poucas repetições e elaborações; estabelece-se uma relação competitiva, pois as diferenças de opiniões são colocadas em oposição, e não compartilhadas.

$\mathrm{Na}$ conversação exploratória, o discurso é dominado por refutações e solicitações de esclarecimentos que expliquem ou justifiquem uma ideia. Essa conversação implica em raciocínio e suas regras básicas necessitam que sejam observados e considerados os pontos de vista de todos os participantes; os pares tratam de forma crítica, mas construtiva, as ideias dos demais, já que as afirmações e 
sugestões são consideradas conjuntamente e o avanço do grupo ocorre por intermédio de negociações coletivas.

Tendo como base essas três formas de conversação, buscou-se identificar a presença delas nos dados da pesquisa.

Um segundo elemento capaz de auxiliar no entendimento do discurso dos alunos é a classificação de possíveis tipos de perguntas feitas por eles em sala de aula. De acordo com Chin e Brown (2002), há duas categorias para tais perguntas: questões de informação básica (factuais ou procedimentais) e perguntas de alto nível cognitivo (wonderment questions). As questões de informação básica factuais demandam somente a retomada de informações e constituem-se, frequentemente, em perguntas fechadas, que não permitem espaço para maiores discussões. Já as questões de informação básica procedimentais solicitam esclarecimentos sobre um dado procedimento ou orientação para a realização de uma determinada tarefa.

As perguntas de alto nível cognitivo, de acordo com Mendonça (2010, p. 36),

exigem uma aplicação ou extensão dos conceitos ensinados, fazer previsões, buscar explicações e causas, identificar e resolver discrepâncias e lacunas no conhecimento. As perguntas de alto nível cognitivo são formuladas quando, durante seus esforços de entendimento, os estudantes tentam lidar com um conhecimento novo ou construir associações internas entre diferentes aspectos desse novo conhecimento. Elas exigem a clarificação de informações complexas ou divergentes vindas de várias fontes ou, ainda, revelam reflexões, curiosidades, cepticismo ou especulação.

Considerando esses referenciais, pretendeu-se categorizar também o tipo de pergunta que os alunos investigados fizeram, considerando que, por hipótese, questões elaboradas pelos próprios estudantes podem ser mais frequentes no interior de um pequeno grupo envolvido na resolução de uma atividade investigativa do que em uma proposta de ensino na qual apenas o professor tem o controle das ações e interações discursivas. Um estudo específico somente sobre as perguntas feitas pelos estudantes na interação em pequeno grupo pode ser visto em Aguiar, Mortimer e Scott (2010).

\section{EXPERIMENTO PARA A DETERMINAC̣ÃO DA ACELERAC̣ÃO DA GRAVIDADE}

Aguiar e Maximo-Pereira (2011) propuseram uma técnica para a realização de medidas de intervalos de tempo sem interferência do experimentador e com precisão da ordem de milissegundos. Ela consiste na utilização de um gravador de som digital em associação com o software de edição de áudio Audacity, disponível gratuitamente na internet em http:/ / audacity.sourceforge.net.

Muitos experimentos de Mecânica podem ser cronometrados por intermédio do som que produzem. Para a medida do tempo de queda de um objeto, uma possibilidade experimental aparece na Figura 1. 
Figura 1: Experimento para medida do tempo de queda de um corpo.

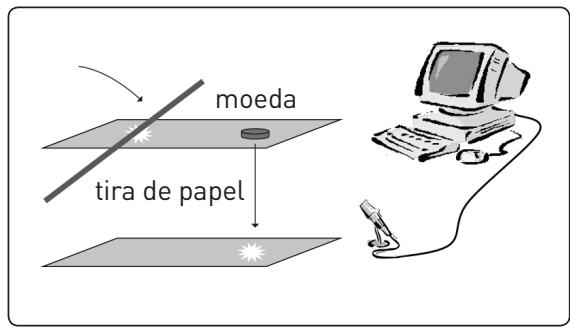

Figura 2: Gravação do som produzido durante 0 experimento.

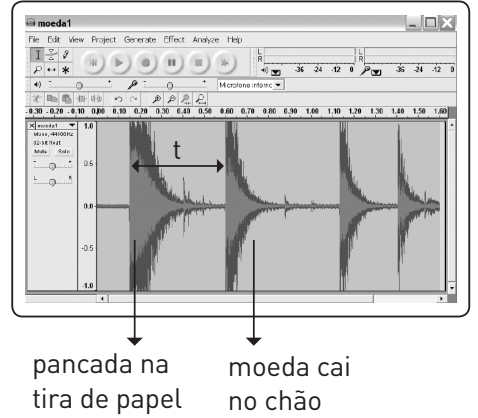

Uma moeda é colocada sobre uma tira de papel a qual é mantida a uma altura $\mathrm{h}$ do solo por uma pessoa que segura com as mãos cada uma das pontas da tira. Em seguida, a tira é golpeada com força (com uma caneta ou régua) próximo a uma de suas extremidades, de modo que seja solta desse lado por conta do impacto. Com isso, a moeda perde a sustentação do papel e cai.

A Figura 2 mostra a tela do software Audacity com a gravação do som produzido nesse processo. Dois pulsos sonoros podem ser vistos (e ouvidos). O primeiro corresponde ao golpe dado na tira de papel, e o segundo, ao choque do objeto com o chão (os pulsos seguintes são produzidos pelos quiques do objeto após a queda e por outros ruídos). O intervalo entre os dois primeiros pulsos é o tempo de queda $t$, medido na escala de tempo (eixo horizontal) da tela do Audacity. Para um objeto que cai de uma altura $h$ (partindo do repouso) e com tempo de queda $t$, podemos determinar o valor da aceleração da gravidade $g$ por

$$
g=\frac{2 h}{t^{2}}
$$

\section{4- DESCRICฺ̃̃O DA ATIVIDADE INVESTIGATIVA}

A atividade investigativa foi aplicada no início do terceiro bimestre do ano letivo de 2009, durante dois tempos consecutivos de aulas regulares de Física, com duração total de cem minutos. A turma participante da atividade era formada por 32 alunos do $2^{\circ}$ ano do Ensino Médio do Centro Federal de Educação Tecnológica Celso Suckow da Fonseca, Unidade de Ensino Descentralizada de Nova Iguaçu (CEFET-NI), Brasil. Os estudantes tinham idades entre 15 e 18 anos e foram organizados em 5 grupos de 6 a 7 integrantes cada para a resolução do seguinte problema proposto a eles: "Como determinar a aceleração da gravidade no CEFET-NI e qual o valor de $g$ aqui?".

Foram disponibilizados alguns materiais que poderiam ser utilizados para a resolução do problema: pequenas bandejas, bolinhas de metal, cubinhos de metal, 
trena, régua, papel, caneta, computador com microfone interno e com o software Audacity. Os alunos foram orientados também a lembrar a matéria de Física ensinada no primeiro bimestre ${ }^{1}$, que poderia ser necessária para a realização da atividade.

O objetivo da atividade era que os alunos se organizassem para pensar sobre a questão coletivamente e que mobilizassem conhecimentos anteriores sobre movimento uniformemente variado e sobre a técnica de medida de tempo mencionada acima para resolver o problema, argumentando cientificamente. Vale lembrar que tal técnica de medição de tempo já havia sido utilizada pelos alunos em experimentos anteriores.

Após a discussão no interior dos grupos (com o auxílio da professora quando solicitado), um aluno de cada grupo apresentou para toda a turma a solução ao problema proposta pelo grupo. A professora foi orientando a discussão coletiva e fazendo as mediações necessárias para auxiliar na resolução do problema. Quando a turma chegou a um consenso, os grupos passaram a realizar a experiência conforme acordado coletivamente. Toda a atividade foi conduzida pela professora na perspectiva do ensino por investigação (AZEVEDO, 2004), com muitos momentos de discussão, reflexão e de protagonismo dos estudantes na resolução ao problema proposto.

\section{ANÁLISE DOS DADOS OBTIDOS}

Neste trabalho, analisamos as interações discursivas que ocorreram entre os estudantes de um dos grupos que participaram da atividade investigativa. Todos os grupos tiveram suas falas gravadas, por intermédio das quais foi possível identificar que, com mais ou menos intensidade, todos eles acolheram o problema colocado pela professora, discutiram entre si e colaboraram para a solução coletiva à questão.

Após a escuta atenta das falas de todos os grupos, foi selecionado para essa investigação o grupo que pareceu ser um dos mais engajados na atividade e o que mais se aproximou da resolução do problema, conforme poderá ser observado mais adiante neste texto. Além disso, ainda que tenha sido feita a análise da interação em pequeno grupo, identificou-se que esse grupo apontou direcionamentos fundamentais no que se refere à resolução de impasses surgidos na discussão com toda a turma (a qual não será objeto de estudo neste trabalho). Tal fato indicou que, de certo modo, a discussão no interior do grupo pode ter sido frutífera a ponto de suscitar posicionamentos dos estudantes em momentos posteriores da discussão e de manter seu nível de engajamento até o fim da atividade.

Com base na transcrição das falas desse grupo, foi estudada a discussão entre os alunos, identificados nas transcrições pelos seguintes nomes fictícios: Silvia, Carolina, Henrique, Solange, Milena e Felipe. As intervenções da professora foram identificadas por Professora. Quando um aluno do grupo se referia a outro pelo nome, alteramos seu nome verdadeiro na transcrição para o nome fictício correspondente. 
De acordo com Cazden (2001), os alunos parecem estar mais dispostos a confrontar ideias novas quando falam em situações em que se situam em pé de igualdade com o interlocutor (por exemplo, com seus pares) do que em situações em que se deparam com uma autoridade (por exemplo, quando se dirigem a seu professor). Na coleta de registros realizada, ao longo de aproximadamente treze minutos de transcrição da interação no pequeno grupo, houve cerca de 300 turnos de fala, envolvendo, com maior ou menor participação de cada um, os seis alunos integrantes do grupo. Houve também algumas mediações da professora, ao propor a atividade e ao ter sua intervenção solicitada pelo grupo.

A aluna Silvia teve 94 turnos de fala; o aluno Henrique, 55; a aluna Carolina, 49; a aluna Solange, 46; o aluno Felipe, 8; a aluna Milena, 8; a Professora, 41. Conforme será mencionado mais adiante, a aluna Silvia foi identificada como sendo uma líder dentro do grupo, o que também é justificado pelo fato de ser quem mais fez intervenções. O número de intervenções da professora foi grande porque a coleta dos registros iniciou-se enquanto ela propunha a atividade e indicava os materiais que poderiam ser utilizados para resolver o problema. Após essa etapa, houve 19 intervenções dela no pequeno grupo analisado.

No entanto, como mencionado anteriormente, nem todos os tipos de conversação e de colaboração dentro de um grupo têm o mesmo valor educativo (MERCER, 1997). Assim, é necessário investigar as falas dos estudantes também de modo qualitativo; a quantidade delas isoladamente não indica o potencial das interações para a aprendizagem, já que podem aparecer distintas formas de conversação na sala de aula e diferentes modos de trabalho no pequeno grupo.

Um olhar geral para as falas dos alunos do grupo analisado indicou um elemento interessante: a formulação de muitas perguntas por parte deles. Enquanto em uma atividade guiada majoritariamente pelo professor, os alunos em geral são chamados a responder perguntas, autênticas ou não, a atividade investigativa proposta possibilitou que os estudantes colocassem também muitas questões no interior do grupo. Esse fato concorda com o exposto em Cazden (2001, p. 115): “A melhor situação para os estudantes darem direcionamentos (ao invés de apenas segui-los) e fazerem perguntas (ao invés de respondê-las) é com os pares." Contudo, esse tipo de situação, por si só, não promove necessariamente uma postura questionadora por parte dos estudantes; é preciso que eles sejam orientados a como fazer questionamentos e a como fazer uso deles para ampliar a compreensão sobre a atividade a ser realizada.

Passando a uma análise mais detalhada das interações discursivas, percebe-se que as primeiras interações entre os alunos para resolver o problema aconteceram para dar conta de uma questão essencial: o entendimento, por todos os componentes do grupo, da questão proposta inicialmente pela professora. Sem essa compreensão inicial, toda a atividade ficaria prejudicada, seu propósito não seria compartilhado por todos, o que poderia dificultar a gestão das ações do grupo e a sua mobilização para a resolução do problema.

A aluna Solange, no turno 5, questionou o fato de o problema proposto ter sido a determinação da aceleração da gravidade na escola onde os alunos estudavam, 
e não em outro lugar. Ela parece desconhecer o fato de que a aceleração da gravidade varia para cada corpo celeste considerado e que, mesmo no caso da Terra, há pequena variação nesse valor conforme a altitude e a latitude em que se esteja. Assim, seu questionamento no turno 5 parece ser, ao menos para ela, uma pergunta de alto nível cognitivo, pois exige a "...extensão dos conceitos ensinados, fazer previsões, buscar explicações e causas...” (MENDONÇA, 2010, p. 36).

Essa interpretação também pode ser feita porque a aluna Silvia, ao responder à pergunta de forma cientificamente adequada, estende o conceito de aceleração da gravidade a outros planetas e faz previsões acerca dos valores possíveis para a aceleração da gravidade na Terra (turnos 6 e 8), no que foi apoiada aluno Henrique (turno 7).

\section{[5] (Solange) A aceleração que ela fala no CEFET, como assim? No CEFET? \\ [6] (Silvia) Em cada lugar tem uma aceleração da gravidade diferente... A aceleração da Terra é diferente da de Marte... \\ [7] (Henrique) É... \\ [8] (Silvia) E diferente em cada ponto da Terra também. Tipo, no Rio de Janeiro é uma coisa, em São Paulo é outra, muda pouca coisa.}

Assim, entende-se que emergiu, dessa discussão, outra das condições favoráveis para o desenvolvimento da conversação entre estudantes, de acordo com Mercer (1997, p. 110): "os participantes devem compreender bem, e de forma compartilhada, a solução e o propósito da atividade”.

Além disso, a aluna Silvia pareceu ter atuado como "parceiro mais capaz", nos termos de Vigotski (2007), já que o questionamento de Solange foi solucionado no interior do grupo, com as considerações de Silvia, sem o conhecimento ou intervenção da professora.

A mesma situação ocorreu a partir do turno 18, enquanto a professora apresentava os materiais que poderiam ser utilizados para a realização da experiência. A aluna Solange apresentou uma nova dúvida, na forma de uma questão básica factual: não sabia o que era uma trena. Ainda que o grupo já tivesse começado a se mobilizar para tentar solucionar o problema proposto, o aluno Henrique percebeu a necessidade de explicar o que era esse instrumento, que estava na lista dos que poderiam ser usados para resolver a questão. $\mathrm{O}$ aluno Henrique também parece atuar como parceiro mais capaz nesse caso, pois explicou com suas palavras o que é uma trena (turno 23).

[18] (Solange) O que é trena?

[19] (Carolina) Aqui, se a gente pegar e, tipo assim, jogar o negócio de uma altura e tinha que ter alguma coisa para medir, algum cronômetro, alguma coisa assim...

[20] (Milena) Boa, boa...

[21] (Solange) Eu acho que é isso.

[22] (Silvia) Acho que não tem relação com o tempo, não... Não tem relação com o tempo...

[23] (Henrique) Trena é uma régua grande de pedreiro...

[24] (Solange) Ah. 
No que se refere ao início da discussão sobre o que fazer para solucionar a questão proposta, as ações que os estudantes entenderam como necessárias à resolução do problema foram: utilizar o programa Audacity (turno 77, Silvia), fazer a experiência (turno 79, Solange), anotar informações (turno 80, Silvia) e usar a matéria ensinada no bimestre anterior (turno 84, Carolina). Além disso, foi identificada a presença da aluna Silvia coordenando o gerenciamento do grupo, pois ainda que Solange e Carolina também tenham proposto ações, foi Silvia quem distribuiu as tarefas - utilizar o programa Audacity (turno 77), anotar informações e organizar as ações (turno 82), separar a matéria do bimestre anterior para consulta (turno 88).

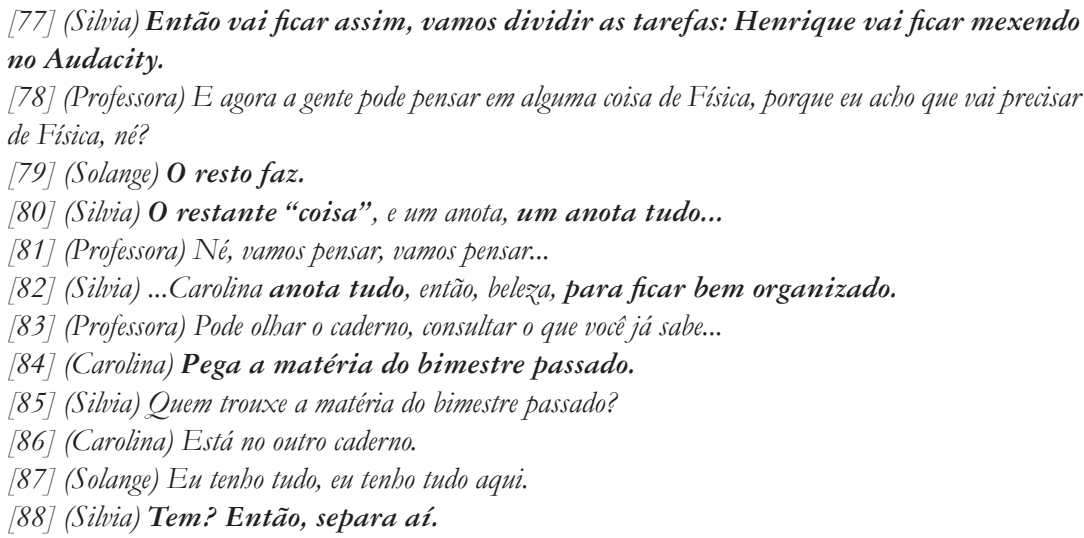

A aluna Silvia, em outros momentos da interação no grupo (turnos 103 e 105), também atuou como líder e organizadora dos turnos de fala, ou seja, ela tentou propiciar que todos falassem de maneira ordenada, conciliando as diferentes ideias.

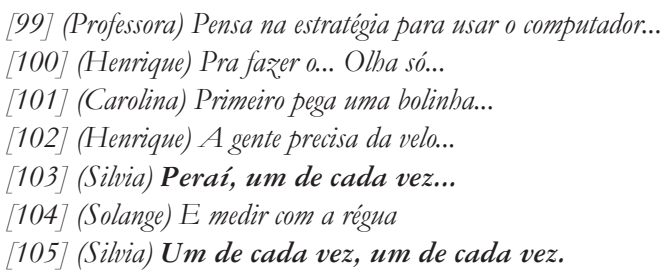

A aluna Silvia pareceu compreender que a atividade deveria "promover a cooperação, e não a concorrência entre os colegas" (MERCER, 1997, p. 110), e atuou para que isso ocorresse.

De acordo com Mercer (1997), para que o trabalho em grupo seja uma atividade educativa bem sucedida, os alunos devem compartilhar as mesmas ideias sobre o que venha a ser importante na discussão e devem ter uma compreensão comum sobre o que se quer atingir com ela. Nesse sentido, os turnos 20, 21, 29 e 33 indicaram que os alunos estavam de acordo com as ideias sugeridas. Nos turnos 19, 27, 30 e 32, o grupo como um todo pareceu manifestar concordância no que se 
refere às variáveis relevantes (altura, tempo, velocidade) e aos procedimentos experimentais (lançar ou soltar a bolinha de certa altura, medir o tempo com algum tipo de cronômetro) necessários para a resolução do problema proposto. Em outras palavras, a conversação que se estabeleceu naquele momento foi acumulativa (MERCER, 1997), pois houve afirmações, repetições e confirmações das ideias e opiniões uns dos outros.

[19] (Carolina) Aqui, se a gente pegar e, tipo assim, jogar o negócio de uma altura e tinha que ter alguma coisa para medir, algum cronômetro, alguma coisa assim...

[20] (Milena) Boa, boa...

[21] (Solange) Eu acho que é isso.

[27] (Carolina) A gente joga a bola e a altura... mede a altura da bolinha aqui e com uma outra bolinha aqui, pum

[28] (Henrique) Gente...

[29] (Solange) Eu acho dez.

[30] (Henrique) Isso é fácil... A gente pega a bolinha, solta de uma determinada altura...

[31] (Professora) Vamos lá, o que que a gente tem? A gente tem papel, a gente tem régua...

[32] (Henrique) A gente pega a bolinha, solta de uma determinada altura, marca o tempo, vê a velocidade e depois joga.

[33] (Carolina) Isso que eu falei.

Foi possível identificar que, para os alunos desse grupo, a resolução do problema proposto consistia na escolha de como realizar a queda da bolinha, fenômeno identificado por eles como sendo necessário para a determinação da aceleração da gravidade, e na determinação do modelo matemático que iria descrever esse movimento.

A esse respeito, os alunos Carolina e Henrique defenderam duas posições diferentes, que foram acolhidas e problematizadas pelos demais integrantes do grupo. Entre os turnos 106 e 110, Carolina expôs a sua ideia, com o auxílio de Silvia.

[106] (Carolina) Então, pega a bolinha, coloca na altura mais alta e mede altura. Ai, tem que deixar ela cair no chão e com o programa do Audacity a gente vê essa velocidade...

[107] (Silvia) Vê tempo, vê o tempo...

[108] (Carolina) É, isso, vê o tempo. Về o mesmo tempo

[109] (Solange) Como é que a gente vai marcar o tempo?

[110] (Carolina) Pelo Audacity.

O aluno Henrique, na sequência, acolheu a ideia de Carolina (Olha só, tem, tem várias formas de fazer, no turno 114), mas explicitou a sua própria, nos turnos 114 e 116. Silvia pareceu não apoiar inicialmente a proposta de Henrique, dizendo que o grupo teria que pensar sobre o que ele estava dizendo (turnos 115 e 117).

[114] (Henrique) Olha só, tem, tem várias formas de fazer. Uma em que eu estava pensando é a gente fazer a mesma coisa. É... Pegar, botar numa altura, numa certa altura, a bolinha, soltar e ver a velocidade média. Depois a gente pode jogar ela numa daquelas fórmulas do...Torricelli...

[115] (Silvia) Calma aí, vamos pensar.

[116] (Henrique) $V$ ao quadrado igual a 2 a delta $S$, para ver a aceleração.

[117] (Silvia) Vamos pensar... 
Tanto no início do turno 114, no qual Henrique disse "tem várias formas de fazer", como nas intervenções de Silvia nos turnos 115 e 117, esse dois alunos pareceram não desconsiderar as falas dos outros membros do grupo, mas avaliá-las criticamente. Esse momento parece ser o início da conversação exploratória, tal como definida por Mercer (1997, p. 116), pois “os pares tratam de forma crítica, mas construtiva, as ideias dos demais".

Para tentar fazer com que o grupo acolhesse sua ideia, Henrique explicou, com a ajuda de Silvia, como faria para determinar o valor da aceleração da gravidade (turnos 154 a 163).

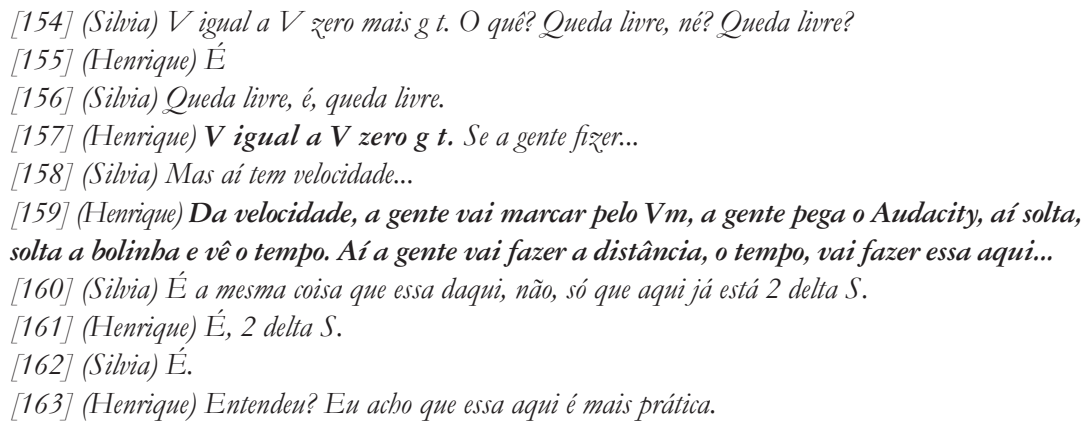

Em sua explicação, Henrique disse que ia usar $\mathrm{V}=\mathrm{V}_{0}+\mathrm{gt}$ (função horária da velocidade no movimento uniformemente variado), sendo inicialmente seguido por Silvia, que apontou, no turno 158, que para utilizar essa relação matemática havia a necessidade de conhecer a velocidade do objeto, o que poderia dificultar a utilização da fórmula. Diante disso, Henrique argumentou, no turno 159, que tal velocidade poderia ser calculada pela velocidade média ( $\mathrm{Vm}$ ). Naquele momento, ficou clara a confusão de Henrique entre os conceitos de velocidade e velocidade média. No entanto, o grupo parece não ter identificado esse problema, pelo menos de forma explícita.

Dando sequência à conversação exploratória, Carolina expôs seu ponto de vista - contrapondo-se à ideia de que a proposição de Henrique era mais prática - e esclareceu o porquê de sua escolha (turno 164, Carolina), no que foi apoiada por Solange (turno 166).

[164] (Carolina) Eu acho que essa aqui [referindo-se à formula $h=1 / 2 g t^{2}$ ] é melhor porque a gente vai ter o tempo, certo? A altura, certo?

[165] (Solange) Só vai faltar o g.

[166] (Carolina) É.

Na sequência dos turnos, Henrique seguiu defendendo a sua ideia, mas Solange, no turno 169, colocou uma pergunta fundamental para uma nova explicitação da limitação da proposta do aluno Henrique: ao fazer uma questão de informação básica procedimental (Como a gente vai achar velocidade?), a resposta que o aluno Henrique lhe forneceu, nos turnos 170 e 172, demonstra que ele seguiu 
confundindo os conceitos de velocidade e velocidade média e que o grupo não foi capaz de identificar esse problema. Portanto, a falta desse conhecimento científico justifica por que a aluna Solange defendeu, no turno 173, que fossem considerados os pontos de vista de ambos, Carolina e Henrique.

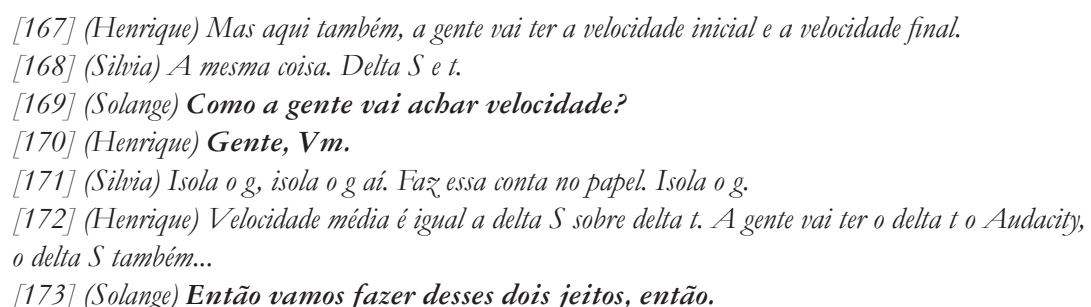

Entre os turnos 174 e 191, o grupo estava mobilizado para tentar contemplar a proposta de Henrique, manipulando algebricamente as expressões matemáticas sugeridas por ele a fim de encontrar uma relação entre variáveis na qual aparecessem aceleração da gravidade e outras grandezas já conhecidas. No turno 191, Silvia mencionou que o resultado que encontrou não foi o esperado e solicitou a presença da professora para resolver o impasse. Enquanto esperava pela professora, Silvia seguiu coordenando as ações do grupo, pedindo, no turno 193, que Solange isolasse o valor da aceleração da gravidade na função horária da posição no movimento uniformemente variado. Solange, então, se vale de uma questão de informação básica procedimental, no turno 194, para saber como se faz isso. Ao mesmo tempo, Carolina aproveita o momento de dúvida por parte de Silvia e Solange para, mais uma vez, defender a sua forma de solução ao problema como sendo a mais fácil (turnos 192 e 196).

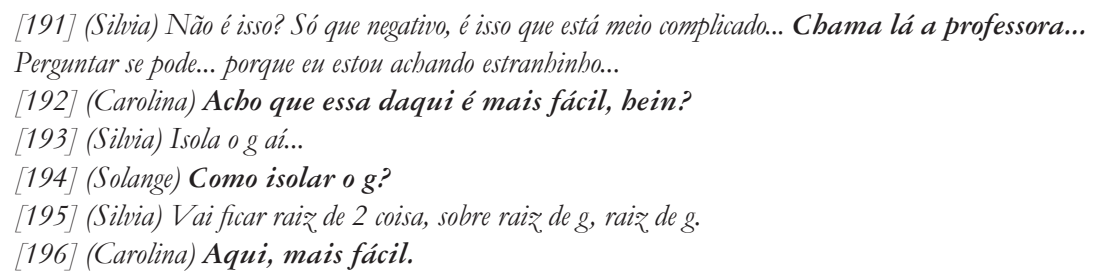

Toda a discussão aqui relatada sobre a escolha do modelo matemático mais adequado para a descrição do experimento proposto pelos estudantes evidenciou que os alunos foram capazes de levantar questionamentos sobre as ideias defendidas por outros, o que, de certo modo, demandou deles a análise crítica tanto de suas próprias concepções, para defendê-las, como das proposições dos outros, para avaliá-las. Tal análise pôde ocorrer porque os alunos já dispunham, em alguma medida, dos conhecimentos específicos necessários à resolução do problema, aos quais eles puderam atribuir sentido em um novo contexto de utilização. 
Como os alunos não conseguiram resolver sozinhos o impasse surgido internamente, a mediação da professora foi solicitada por Silvia na tentativa de solucionar a seguinte dúvida: acatar a ideia de Henrique, mesmo sendo "mais complicada" e chegando a um resultado "estranho" (nas palavras de Silvia), ou acolher a proposta de Carolina, aparentemente mais fácil, segundo a própria aluna, mas que não mobilizou o grupo como a proposta de Henrique?

Mais uma vez, Silvia parece liderar as ações, decidindo o momento de recorrer à autoridade e ao conhecimento da professora. É interessante notar também que o auxílio da professora, pedido somente no turno 191, parece indicar um alto engajamento e compromisso dos estudantes com a atividade, pois somente após longa discussão no grupo a sua ajuda foi requerida.

A indicação de uma direção a ser seguida diante das formas de resolver o problema, apresentadas por Carolina e Henrique, foi realizada pela professora, que fez pequenas intervenções de concordância e uma pergunta essencial (turno 210), cuja resposta, fornecida não pela professora, mas por Solange e Silvia (turnos 213 e 214, respectivamente), sinalizou um novo equívoco conceitual na proposta de Henrique: confusão entre os conceitos de variação de velocidade e velocidade média.

[197] (Silvia) Professora, calma aí, a gente está tentando pegar uma fórmula que tenha gravidade, pra poder descobrir.

[198] (Solange) A gente quer isolar este daqui.

[199] (Silvia) Só que a gente pegou aquela de queda livre. Delta...é...

[200] (Henrique) V igual a V zero $g$ t.

[201] (Silvia) Só que vai ficar negativo.

[202] (Professora) Não tem problema.

[203] (Carolina) Ó!

[204] (Professora) Aham.

[205] (Carolina) Pelo Audacity a gente pegaria o tempo.

[206] (Professora) Aham.

[207] (Henrique) E calcularia a velocidade média.

[208] (Professora) Aham.

[209] (Henrique) E jogaria aqui.

[210] (Professora) Mas essa velocidade aqui, delta V, é a velocidade média?

[211] (Silvia) É a variação, variação de velocidade.

[212] (Professora) Mas essa variação é a velocidade média?

[213] (Solange) Acho que não.

[214] (Silvia) Não.

Com suas mediações, a professora não apontou diretamente o problema conceitual compartilhado pelo grupo, mas conseguiu fazer com que os próprios alunos percebessem as inconsistências da proposta do aluno Henrique e buscassem outra direção.

Esse fato deu ensejo ao retorno da proposta de Carolina, a partir do turno 215, e a discussão caminhou no sentido de se acatar a proposta dessa aluna, com a participação de Silvia e com as intervenções da professora. Entre os turnos 215 
e 219, Carolina e Silvia identificaram a formulação matemática apropriada para a resolução do problema, no que foram acompanhadas pela professora. Quando o grupo foi indagado sobre o tipo de movimento descrito pela formulação matemática escolhida, Carolina iniciou a resposta (turno 222), que foi complementada por Silvia. A aluna concluiu que se trata de um movimento uniformemente variado, chamado de "MUV" por ela (turno 223).

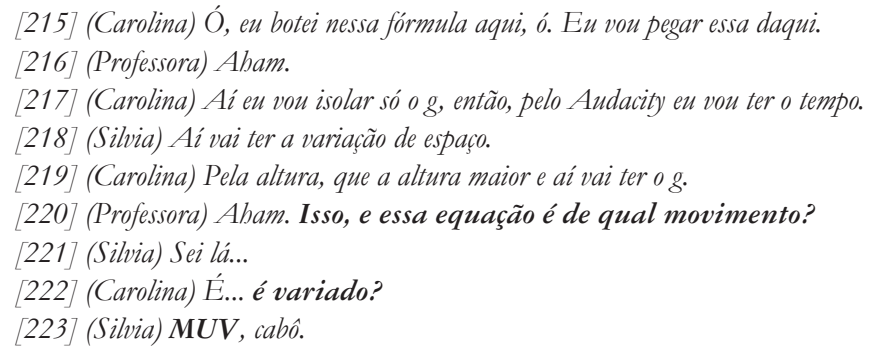

Sobre a forma de realizar o experimento, os alunos chegaram a um consenso: deveriam abandonar a bolinha de certa altura e medi-la; medir o tempo de queda da bolinha; calcular a aceleração da gravidade pela função horária da posição no movimento uniformemente variado. Contudo, o modo de fazer a medição de tempo não foi totalmente explicitado por eles. Quando a professora perguntou como o grupo mediria o tempo de queda da bolinha, Carolina e Silvia, nos turnos 231 e 232, mencionaram que o intervalo de tempo seria medido pelo Audacity. A professora questionou como seria feita essa medição (turno 233) e Solange e Silvia não conseguiram responder. A professora, então, orientou o pensamento das alunas (turno 236) no sentido de que elas se lembrassem do princípio de utilização do Audacity (gravação do som produzido nos experimentos), o qual foi rapidamente retomado por Solange, Silvia e Carolina (turnos de 237 a 239). Silvia indicou que o som seria o da bolinha caindo no chão (turno 240). Felipe mencionou a necessidade de um som quando a bolinha fosse abandonada (turno 243).

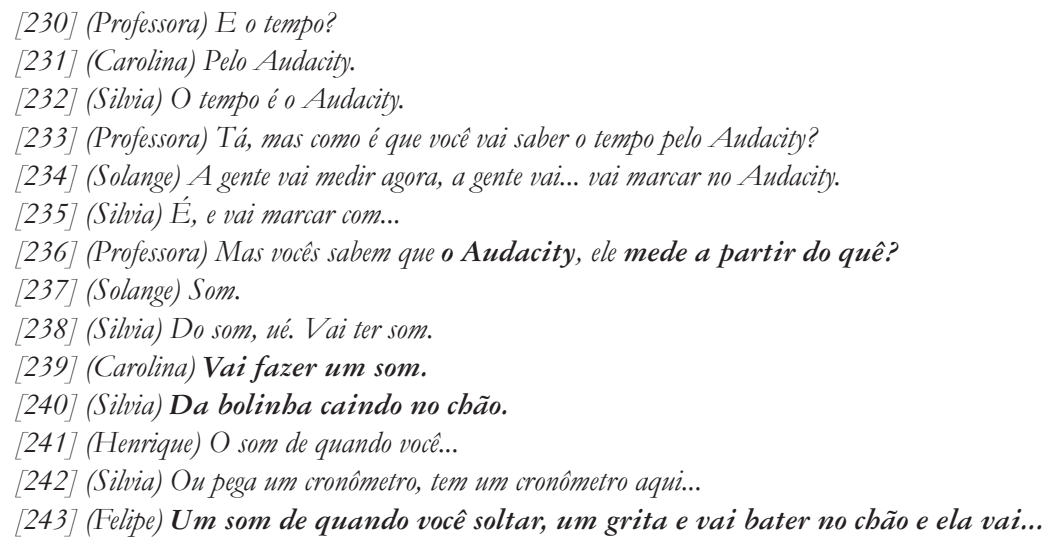


Com a ajuda de Professora (turno 246), Silvia reformulou sua proposta, sugerindo que se colocasse o pires de metal (um dos materiais também disponibilizados para o experimento) no chão, para que o barulho da queda da bolinha fosse mais intenso (turno 249), ideia que foi acolhida por todo o grupo (turnos de 250 a 253). Henrique pareceu identificar essa etapa como a última para a solução ao problema (turno 254).

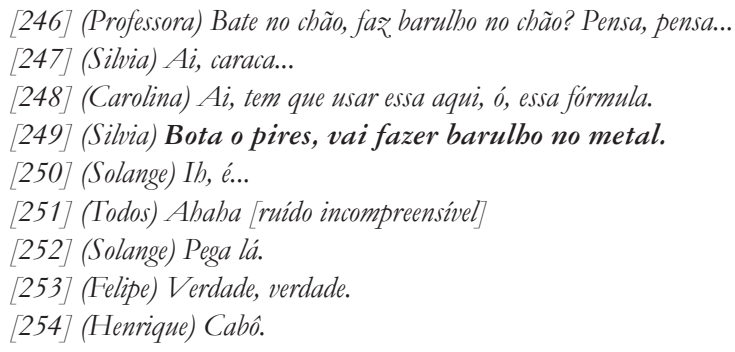

No entanto, Milena retomou a fala de Felipe no turno 243 e apontou que deveria existir, também, além do barulho no chão, feito quando a bolinha atinge o pires, um barulho inicial (turno 262). Milena, no turno 264, fez menção ao experimento anterior, de determinação da velocidade de uma bola de futebol em um chute (AGUIAR e MAXIMO-PEREIRA, 2011), no qual o software Audacity também foi utilizado. A aluna citou a forma como o barulho inicial foi feito nessa outra experiência, no que foi apoiada por Felipe (turno 265). Todavia, o grupo pareceu não dar muita importância à questão levantada por Milena e Felipe, já que Solange continuou preocupada com o cálculo de g (turno 263).

[262] (Milena) E o barulho inicial?

[263] (Solange) Aqui, já tá isolado esse g.

[264] (Milena) Ab, é, do pé com a bola?

[265] (Felipe) É isso que eu tô falando, tem que ter um barulbo inicial pra depois ter um final.

É interessante notar que, ainda que Milena e Felipe tenham sido os integrantes do grupo com menor participação na discussão (apenas 8 turnos de fala para cada um), eles levantaram, nesse ponto, questões essenciais à resolução final do problema, como a pergunta de alto nível cognitivo que Milena colocou no turno 262, sobre como fazer um ruído inicial a fim de ser possível medir o tempo de queda da bolinha com o uso do Audacity. Assim, ainda que não tenham participado ativamente das discussões, parecem estar interagindo nelas mesmo de forma silenciosa, pois acompanharam o desenvolvimento da resolução do problema pelos outros integrantes do grupo a tal ponto que foram capazes de fazer intervenções em pontos cruciais para a solução da questão, mas que não foram reconhecidas como tais pelos integrantes mais participativos nas interações discursivas.

A pouca importância que o grupo deu às colocações de Milena e Felipe ficou evidenciada quando percebemos que Felipe trouxe o tema de volta para a 
discussão somente no turno 288, quando o procedimento utilizado no experimento, inicialmente feito com o uso do Audacity, foi, mais uma vez, retomado.

\section{[288] (Felipe) Não tem que fazer um barulbo inicial, que nem foi naquela da bola?}

Passando a se dedicar à questão de como fazer um barulho inicial, para ser um indicativo do instante inicial do movimento, os alunos continuaram com a discussão, mas não conseguiram, em pequeno grupo, elaborar uma estratégia para isso. Foi com a mediação da professora, na interação com toda a turma, que os alunos chegaram à solução completa do problema proposto. Depois, realizaram a experiência novamente em pequenos grupos e determinaram o valor da aceleração da gravidade na escola onde estavam.

\section{CONSIDERAC̣̃̃ES FINAIS}

Neste trabalho, foi realizada a análise das interações discursivas desencadeadas em pequeno grupo durante uma atividade investigativa sobre determinação da aceleração da gravidade. Com base em algumas contribuições teóricas, foi possível caracterizar a dinâmica da interação entre os alunos, tanto no que se refere a formas de conversação estabelecidas entre eles quanto a tipos de perguntas por eles colocadas.

Foi possível identificar o caráter acumulativo e o caráter exploratório (MERCER, 1997) na conversação dos estudantes e que alguns deles apresentaram-se como parceiros mais capazes para os colegas, oferecendo auxílio para o entendimento da situação proposta (de modo semelhante ao que faria o professor). Por conta disso, a atividade investigativa e, em especial, a interação em pequeno grupo, pareceram incidir na ZDP dos alunos. Observou-se, assim, a importância que a interação entre pares pode ter no desenvolvimento cognitivo e nos processos de construção mediada de sentidos em ciências.

A descrição e a problematização dos turnos de fala possibilitaram o entendimento de como os alunos foram construindo conhecimentos e desenvolvendo habilidades coletivamente, objetivando dar conta do problema proposto na atividade investigativa. Os estudantes apresentaram grande engajamento e envolvimento na tarefa proposta, buscando solucioná-la mediante a negociação com os elementos que haviam sido disponibilizados pela professora previamente (o uso do software Audacity e de conteúdos relativos à cinemática, de forma geral e, em especial, à queda dos corpos).

A questão colocada e os direcionamentos dados pela professora conseguiram mobilizar os alunos do grupo para a realização da atividade. Ainda que não tenhamos analisado profundamente as intervenções da professora, ela realizou mediações essenciais, no sentido de esclarecer impasses que não puderam ser resolvidos pelos alunos sozinhos. Ela não forneceu respostas prontas, mas encaminhou a discussão de modo que os próprios estudantes reconsiderassem suas posições, as 
avaliassem criticamente e, desse modo, pudessem avançar no desenvolvimento da estratégia de resolução do problema e em uma compreensão coletiva.

Perguntas de informação básica e de alto nível cognitivo (CHIN e BROWN, 2002) foram observadas no discurso dos estudantes. É interessante notar que questões de alto nível cognitivo foram colocadas por alunos que participaram menos ativamente da discussão (Solange, Milena e Felipe). Tal fato parece expressar o esforço de entendimento que esses estudantes fizeram para lidar com novos conhecimentos, novas situações e para estabelecer relações a fim de resolver o problema colocado. Tudo isso indica a possibilidade de considerar que houve engajamento na atividade mesmo por parte dos alunos que menos falaram no pequeno grupo.

Além disso, Felipe e Milena, que pouco participaram ao longo das discussões no interior do grupo analisado, levantaram, ao final da interação em pequeno grupo, aspectos fundamentais para a resolução do problema, os quais não foram sequer apontados como relevantes pelos alunos mais envolvidos na discussão. Também foi observada certa resistência dos alunos mais participativos em acatar tais ideias ou em pensar sobre as questões levantadas pelos que menos falaram no grupo. Tal fato aponta para a necessidade de que sejam realizadas mais pesquisas sobre o papel e o lugar dos que menos falam nas interações em pequeno grupo e sobre as relações ou fatores estabelecidos que podem levar (ou não) os alunos a se manifestar em atividades de discussão ou de caráter mais aberto e problematizador.

Por tudo isso, considera-se que a atividade investigativa foi frutífera, pelo menos na etapa e no grupo analisados, pois os alunos em pequeno grupo conseguiram dar conta de diferentes partes da solução do problema (elaboração do experimento, utilização de estratégias de medição, escolha do modelo matemático que descrevia o fenômeno observado). Contudo, vale lembrar que a resolução final da questão ocorreu apenas no grande grupo, com toda a turma participando e com novas mediações da professora, o que evidencia que todos os momentos de uma atividade investigativa são essenciais para a resolução do problema. Assim, a pesquisa corrobora com os resultados de pesquisas anteriores sobre o potencial do ensino por investigação para a aprendizagem de ciências e para o desenvolvimento do poder de argumentação dos estudantes (HODSON, 1992; JIMÉNEZ ALEIXANDRE, 2010).

Muitas pesquisas no campo da análise do discurso em aulas de ciências costumam centrar suas análises no papel e nas intervenções dos professores (EDWARDS, 1990; MORTIMER e SCOT'T, 2002), com pouca ênfase ao que fazem os alunos (CANDELA, 1999). Como ainda se sabe pouco sobre como as interações entre pares podem contribuir para a emergência de uma solução a um problema proposto, nosso estudo pode oferecer alguma contribuição a esse respeito.

No que concerne a implicações desta pesquisa para o ensino de ciências, conhecer de que modo ocorrem as interações discursivas entre os estudantes pode auxiliar o professor a planejar suas mediações de forma a conduzir a discussão considerando que os alunos são capazes de propor questões uns aos outros, elaborar respostas adequadas a elas, organizar-se para trabalhar coletivamente, na 
busca pela solução ao problema proposto. Em outras palavras, nos termos de Vigotski (2009), saber aquilo que os alunos são capazes de realizar em interação com outros, quer sejam seus pares ou seu professor, permite a este último orientar seu ensino para que incida na ZDP dos estudantes, de forma a auxiliar a contínua ampliação dessa zona.

\section{Agradecimentos}

Agradeço ao professor doutor Marcelo Giordan, da Faculdade de Educação da Universidade de São Paulo, por me apresentar aos principais referencias teóricos utilizados neste texto, e aos pareceristas do artigo, que contribuíram de forma substancial para a pesquisa aqui relatada.

\section{NOTA}

${ }^{1}$ A matéria de Física, estudada no primeiro bimestre, consistiu em conceitos básicos sobre movimento e sobre cinemática escalar.

\section{REFERÊNCIAS}

AGUIAR, C. E. M.; MAXIMO-PEREIRA, M. Using the Sound Card as a Timer. The Physics Teacher, v. 49, p. 33-35, 2011.

AGUIAR, O; MORTIMER, E. F; SCOT'T, P. Learning from and responding to students' questions: the authoritative and dialogic tension. Journal of Research in Science Teaching, v. 47, n. 2, p. 174-193, 2010.

AZEVEDO, M. C. P. S. Ensino por investigação: problematizando as atividades em sala de aula. In: CARVAlHO, A. M. P. (Org). Ensino de Ciências. São Paulo: Pioneira Thomson Learning, p. 19-33, 2004.

CANDELA, A. Ciencia en el aula. Los alumnos entre la argumentación y el consenso. Cidade do México: Paidós, 1999. 299 p.

CAZDEN, C. B. Classroom discourse: the language teaching and learning. 2. ed., Portsmouth: Heinemann, 2001. $216 \mathrm{p}$.

CHIN, C.; BROWN, D. Student-generated questions: A meaningful aspect of learning in science. International Journal of Science Education, v. 24, p. 521-549, 2002.

DANIELS, H. Vygotsky e a pedagogia. Trad. Milton Camargo Mota. São Paulo: Edições Loyola, 2003. 246 p.

EDWARDS, D. El papel del professor en la construcción social del conocimiento. Revista Investigación en la Escuela. v. 10, p. 33-50, 1990.

HODSON, D. In search of a meaningful relationship: an exploration of some issues relating to integration in science and science education. International Journal of Science Education, London, v. 14, n. 5, p. 541-566, 1992.

JIMÉNEZ ALEIXANDRE, M. P. 10 ideas claves: competencias en argumentación y uso de pruebas. Barcelona: Graó, 2010. 200 p.

LEMKE, J. L. Talking science: language, learning, and values. Norwood, New Jersey: Ablex Publishing Corporation, 1990. 276 p.

MEHAN, H. Learning Lessons. Cambridge, MA: Harvard Press, 1979. 227 p.

MENDONÇA, D. H. Atividade discursiva em sala de aula: contribuições das perguntas dos estudantes na construção de conhecimento científico. 2010. Dissertação (Mestrado em Educação) - Faculdade de Educação, Universidade Federal de Minas Gerais, Belo Horizonte, 2010. 
MERCER, N. La construcción del conocimiento: El habla de profesores y alumnos, Barcelona: Paidós, 1997. $144 \mathrm{p}$.

MORTIMER, E. F.; SCOTTT, P. Atividade discursiva nas salas de aula de ciências: uma ferramenta sociocultural para analisar e planejar o ensino. Investigações em Ensino de Ciências. Porto Alegre, v. 7, n. 3, p. 283-306, 2002.

MORTIMER, E. F.; SCOTT, P. H. Meaning making in secondary science classrooms. Maidenhead: Open University Press, 2003, $141 \mathrm{p}$.

NEWMAN, D.; GRIFFIN, P.; COLE, M. The Construction Zone: working for Cognitive Change in School. New York: Cambridge University Press, 1989. 188 p.

ROTH, W. M. Talking science: language and learning in science classrooms. Nova Iorque: Rowman \& Littlefield publishers Inc, 2005. 256 p.

VIGOTSKI. L. S. Formação social da mente. São Paulo: Martins Fontes, 2007. 182 p.

VIGOTSKI, L. S. A construção do pensamento e da linguagem. 2. ed., São Paulo: WMF Martins Fontes, 2009, 494 p.

Data de Recebimento: 07/06/2012

Data de Aprovação: 01/04/2013

Data da Versão Final: 03/04/2013 